\title{
Telomerase activity in pregnancy complications (Review)
}

\author{
PERSEFONI FRAGKIADAKI ${ }^{1}$, DIMITRIOS TSOUKALAS ${ }^{1}$, IRINI FRAGKIADOULAKI $^{1}$, CHRISTOS PSYCHARAKIS $^{1}$, \\ DRAGANA NIKITOVIC ${ }^{2}$, DEMETRIOS A. SPANDIDOS ${ }^{3}$ and ARISTIDES M. TSATSAKIS ${ }^{1}$ \\ ${ }^{1}$ Center of Toxicology Science and Research, University of Crete; ${ }^{2}$ Laboratory of Anatomy-Histology-Embryology \\ and ${ }^{3}$ Laboratory of Clinical Virology, School of Medicine, University of Crete, Heraklion 71003, Greece
}

Received March 29, 2016; Accepted May 2, 2016

DOI: $10.3892 / \mathrm{mmr} .2016 .5231$

\begin{abstract}
Telomeres are specific DNA regions positioned at the ends of chromosomes and composed of functional noncoding repeats. Upon cell division, the telomeres decrease in length by a preordained amount. When the telomeres become critically short, cells lose the ability to divide and enter a specific functioning mode designated as 'cellular senescence'. However, human tissues express an enzyme that deters the shrinking of the telomeres, the telomerase. Due to its ability to maintain telomere length, the telomerase slows down and possibly suspends the aging of the cells. In regard to this, solid evidence demonstrates that female human fertility decreases with increased maternal age and that various adverse factors, including alterations in telomerase activity, can contribute to age-associated infertility in women. The fact that telomerase activity is regulated in a time- and location-dependent manner in both embryo and placental tissues, highlights it potential importance to the successful completion of pregnancy. Since maternal age is a crucial determining factor for the success of in vitro and in vivo fertilization, numerous studies have focused on telomerase activity and its correlation with mammalian fertilization, as well as the following cleavage and pre-implantation developmental processes. Associations between telomerase activity and pregnancy complications have been previously observed. Our aim in this review was to summarize and critically discuss evidence correlating telomerase activity with pregnancy complications.
\end{abstract}

\section{Contents}

1. Introduction

2. Telomerase activity during in vivo and in vitro fertilization

3. Telomerase activity in intrauterine growth restriction

4. Telomerase activity in hypoxia

Correspondence to: Professor Aristides M. Tsatsakis, Center of Toxicology Science and Research, University of Crete, Voutes, Heraklion 71003, Greece

E-mail: toxlab.uoc@gmail.com

Key words: telomerase activity, telomere length, intrauterine growth restriction, maternal nutrition, hypoxia
5. Telomerase activity and stress exposure in intrauterine life

6. Telomerase activity and maternal nutrition

7. Conclusions

\section{Introduction}

Telomeres are specific sections of DNA at the end of chromosomes comprised of tandem DNA repeats (TTAGGG). Their biological role is to prevent DNA shortening, protect chromosomes from inappropriate DNA fusions, as well as DNA breaks in order to maintain genomic integrity and stability (1). Importantly, upon each cell division, telomere length (TL) decreases by 50-200 base pairs, which together with cell aging, ultimately results in a crucial TL point which triggers chromosomal fusions and/or apoptosis (2). Telomeric integrity is maintained by the specific activity of telomerase, a cellular holoenzyme. Telomerase, consists of two subunits, an enzymatic protein component, telomerase reverse transcriptase (TERT), that adds the telomeric DNA repeats onto the end of chromosomes, and an telomerase RNA template component (TERC), that serves as a template for telomeric DNA synthesis (3). Due to the fact that TERT is responsible for telomerase activity (TA), its expression is tightly regulated, being highly expressed only in periodically or continuously renewing tissues, such as in cells of the hematopoietic system, germ cells, the epidermis and tumors. Contrary to TERT, TERC is widely expressed in all types of cells, but is unable to induce TA (4).

The complex cell aging system regulates the longevity of cells, as well as senescence. Without functional telomerase, a typical 'dividing' cell will exhibit progressive telomere shortening, which upon reaching a 'critically' short TL, results in telomere-dependent replicative senescence and in an inability to divide further (4). It is interesting to note that although the word 'aging' is usually associated with old age, aging in the sense of telomeres is a life-time phenomenon that begins even before birth. Age-related diseases manifest mostly in old age; however, the aging process at the cellular level can be viewed as a lifelong progression (5). Importantly, premature aging phenotypes, collectively termed 'telomere syndromes' (6), can be induced by rare mutations in human TERT (hTERT). Furthermore, hTERT overexpression in normal human fibroblasts has been shown to protect the cells from apoptosis and necrosis (7). Nonetheless, some adverse factors which have been established to cause telomere dysfunction, telomere uncapping or other types of DNA 
damage, such as oxidative stress, can induce premature cell senescence without the presence of critically short telomeres (8).

Telomerase and telomeres functions, due to their roles in apoptosis and senescence, have been examined in many aspects of reproduction biology, such as fertilization, placental development, stress and hypoxic conditions during pregnancy, as well as premature aging following intrauterine growth restriction (IUGR).

\section{Telomerase activity during in vivo and in vitro fertilization}

It is well established that female human fertility declines with increasing maternal age and that various adverse factors can contribute to aging-associated infertility in women (9). Oocyte defects, such as chromosome abnormalities (aneuploidy), are a major cause of age-related decline in female fertility as they severely impair embryo implantation and development (10). Numerous studies have focused on TA and its correlation with mammalian fertilization, as well as following the cleavage, and pre-implantation development processes. Importantly, Wright et al (11) demonstrated that TA exists in fetal, newborn, and adult testes and ovaries, but not in mature spermatozoa or oocytes. In human somatic cells grown in vitro or during replicative aging in vivo, telomeres erode to shorter and shorter lengths and continually decreasing levels of TA are detectable (12).

According to Liu et al (13), aberrant cleavage and increased cytofragmentation are significantly higher in homozygotic telomerase knockout $\left(\mathrm{TR}^{-/}\right)$eggs as compared to wild-type eggs. From both in vivo and in vitro fertilization (IVF) experiments, it appears that the absence of TA leads to telomere dysfunction, which in turn results in aberrant fertilization and the cleavage of $\mathrm{TR}^{-/-}$gametes (13).

Luteinized granulosa cells (GCs) surround the oocyte and are major somatic cell components of the ovarian follicle. TA is further evidence of the stemness of normal, non-cancer cells in the ovaries $(13,14)$. Successful maturation, fertilization and pre-implantation embryonic development depends on a regulated programme of oocyte growth and differentiation coordinated with the development and differentiation of the surrounding GCs (15). Importantly, it has been demonstrated that TERT is expressed by GCs at all stages of ovarian follicle development $(16,17)$. However, TERT mRNA expression and TA in GCs have been found to decrease with age and basal serum follicle stimulating hormone levels (18). Indeed, the low level of TA in the human ovaries was found to be related to the age-related primordial follicle depletion and it was suggested that TA may be used as a marker of the ovarian functional age (19). Importantly, studies have demonstrated that oocyte development is related to the TA of peripherally residing GCs. GCs play an important role in the maturation of oocytes and are closely associatd with their reproductive quality $(20,21)$. Interestingly, TA was found to be highest in the GCs of the small preantral follicles, and to decrease subsequently through different stages of antral development (22). Moreover, it was shown that the relative TL was longer in GCs from mature oocytes compared with GCs from immature oocytes in humans (23). Upon measuring TA in human GCs obtained from IVF and intracytoplasmic sperm injection cycles, it was demonstrated that the rates of oocyte maturation and good-quality embryo generation increased in a TA level-dependent manner (24). Indeed, the same authors postulated that women with a high level of TA had a greater likelihood of becoming pregnant than those with non-detectable or low levels of TA (24). Along the same lines, the lack of TA in GCs is associated with occult ovarian insufficiency (25). Finally, in GCs obtained from the same individuals, it was shown that TA predicts IVF treatment outcomes better than TL (26). Importantly, TL in human eggs was found to predict cytoplasmic fragmentation in embryos suggesting that telomere shortening induces apoptosis in human prei-mplantation embryos, well in accordance with a telomere theory of reproductive senescence in women (27). This data collectively suggest TA/TL of luteinized GCs is positively correlated with clinical pregnancy rate and, indicate that TA of ovarian luteinized GCs could help health workers to predict the clinical outcomes of IVF treatment.

\section{Telomerase activity in intrauterine growth restriction}

During normal pregnancies, a decrease in TA activity when comparing the early gestation period ( $<10$ weeks), with the late gestation period ( $>10$ weeks), is observed (28). Thus, placenta and chorionic villi specimens from the first trimester of gestation exhibit significantly more TA than placenta and chorionic villi specimens from the second and third trimester during gestation (29,30). Specifically, a high TA was identified in trophoblast cell fractions of the chorion, suggesting that this fraction is a major source of TA activity (31). Additionally, the expression of hTERT was observed in chorions from early stages of gestation, but not in the placenta at the late stages of gestation, with a close correlation between TA and hTERT expression (31). A number of studies have been undertaken to correlate TA in pregnancies with IUGR. IUGR is a common pregnancy complication, which can be defined as the failure of the fetus to reach the size for which it is genetically programmed. Typically, IUGR affects 5-10\% of all pregnancies (32). Delayed growth puts the fetus at risk during pregnancy and is associated with adverse outcomes during delivery and to neonate health problems. These may include a low birth weight, difficulty in handling the stress of vaginal delivery, decreased oxygen levels, hypoglycemia, low resistance to infection, low Apgar scores (a test given immediately after birth to evaluate the newborn's physical condition and determine the need for special medical care), breathing problems associated with meconium aspiration (inhalation of stools passed while in the uterus), difficulties in maintaining body temperature, an abnormally high red blood cell count, long-term growth problems, and in the most severe cases, IUGR can lead to still birth (33).

Interestingly, only weak TA was detected in the placenta and chorionic villi specimens from women with pregnancies complicated by IUGR $(34,35)$. Indeed, hTERT mRNA expression was detected in the placenta and chorionic villi specimens during the first, second and third trimester of gestation in normal pregnancies, whereas copy numbers of hTERT were significantly lower in placenta specimens from women with pregnancies complicated by IUGR (21). The expression of hTERC was observed in chorions obtained during early and late gestation and was not linked to TA (31). On the other hand (36), an analysis of the TERC telomerase subunit gene copy number in placentas from pregnancies complicated by IUGR revealed that the TERC gene copy number was decreased in trophoblasts in placentas from women with pregnancies complicated by IUGR, and it was thus suggested that this may promote senescence in trophoblasts in placentas from pregnancies complicated by IUGR. 
In accordance with these data, a decreased TL was observed in placenta samples collected from women with pregnancies complicated by IUGR (37). Furthermore, a decreased TA in placentas from women with pregnancies complicated by IUGR was associated with increased apoptosis (34).

Data collected from twins affected by growth discordance shed further light on these associations. Twins affected by growth discordance exhibit significant differences in their growth rate and size even though they develop in the same intrauterine environment (38). Importantly, birth weight discordance amongst twins is closely correlated to perinatal morbidity and mortality (39). TA activity was also investigated in twins affected by growth discordance. Thus, specimens from placental tissues from twins affected by growth discordance ( $>20 \%$ weight difference) or not ( $<20 \%$ weight difference) were collected after birth, and TA was analyzed (40). The results revealed that in the growth discordant group, TA was significantly higher in the larger twin than in the smaller twin (40).

\section{Telomerase activity in hypoxia}

Oxygen is a necessity for life; yet, it is toxic to cells when dysregulated. Thus, both high and low levels of oxygen are deleterious to developing embryos. In normal pregnancies, in early gestation, the fetus and placenta exist in a relatively hypoxic environment with an ambient $\mathrm{pO}_{2}<20 \mathrm{mmHg}$ (41). The low oxygen tension favors cell proliferation and angiogenesis in the placenta, whereas it simultaneously supports vasculogenesis, hematopoiesis and chondrogenesis of the developing fetus $(42,43)$. Upon establishing intervillous circulation at approximately 10-12 weeks of gestation, oxygen tension rises to 40-80 $\mathrm{mmHg}$ and remains in this range throughout the second and third trimesters. In order to support normal placental function and fetal development, the placenta adapts to the alterations in oxygen levels by the modulation of hypoxia inducible factor- $1 \alpha$ (HIF-1 $\alpha$ ) expression and by increasing cellular antioxidant defenses (44). Thus, restricted oxygen availability is normal and necessary in utero; however, excessive fetal hypoxia leads to adverse outcomes, including fetal death, IUGR and low birth weight (45). Intrauterine hypoxia occurs when the fetus is deprived of an adequate supply of oxygen. Indeed, intrauterine hypoxia may be due to a variety of causes, including prolapse or occlusion of the umbilical cord, placental infarction, hypertension, anemia, pulmonary disease, preeclampsia, as well as maternal smoking (46). Importantly, intrauterine hypoxia can cause cellular damage within the central nervous system and is associated with a reduced total brain volume and altered cortical volume and structure, a decrease in the total number of cells and myelination deficits (47). This results in an increased mortality rate, including an increased risk of sudden infant death syndrome (SIDS). Moreover, oxygen deprivation in the fetus and neonate have been implicated as either a primary or as a contributing risk factor in numerous neurological and neuropsychiatric disorders such as epilepsy, attention deficit hyperactivity disorder (ADHD), eating disorders and cerebral palsy, as well as in the later development of neurodegenerative diseases (48).

HIF-1 is a transcription factor of major importance in the cellular response to oxygen deficiency with specific roles during embryogenesis (49). HIF-1 is a heterodimeric complex composed of the two basic helix-loop-helix PAS domain (bHLH-PAS) subunits HIF-1 $\alpha$ and HIF-1 $\beta$ (50). The HIF-1 $\alpha$ gene is constitutively transcribed under hypoxic conditions and determines HIF-1 biological activity (51), whereas the HIF-1 $\beta$ subunit dimerizes with several different bHLH-PAS proteins and is continuously expressed (50). HIF-1 targets genes that encode proteins which regulate oxygen homeostasis and are critical for developmental and physiological processes in hypoxic environments (51). Indeed, HIF-1 activity is critical for normal fetal development, as it has been shown that murine embryos lacking functional HIF-1 die on/or before E10.5 (52). An important issue to resolve is the existence of a correlation between HIF-1 and TA. Indeed, HIF-1 $\alpha$ expression was detectable, as demonstrated by western blot analysis, in first trimester placenta samples, but not in placental samples from the second and third trimester $(53,54)$. Accordingly, hTERT protein expression was increased in placental tissues before 10 weeks than in placental tissues after 10 weeks of gestation (54). In vitro Studies have suggested that hypoxia upregulates both HIF-1 $\alpha$ expression and TA. Thus, TL distribution in HUVECs under hypoxic conditions seems to be regulated by a balance between telomere attrition by hypoxia and telomere elongation by enhanced TA acting on telomeres (55). Indeed, Coussens et al (56) demonstrated that HIF-1 $\alpha$ affects telomerase regulation in murine embryological stem cells and these authors suggested that HIF-1a may have a physiologically relevant role in the maintenance of functional levels of telomerase in stem cells (56). Furthermore, it was demonstrated that the hTERT promoter region contains two HIF-1 consensus motifs, which are essential for hTERT transactivation by HIF-1. The introduction of an antisense oligonucleotide for HIF-1 diminishes hTERT expression during hypoxia, indicating that the upregulation of hTERT under hypoxic conditions is directly mediated through HIF-1 (54). Thus, Nishi et al (54) suggested that the regulation of hTERT promoter activity by HIF-1 represents a mechanism for trophoblast growth during hypoxia according to the previous data; there are two possibilities about the association between hypoxia induction and TA. DNA damage in the telomere region can be induced by hypoxia, which would result in HIF-1-induced telomerase expression in order to heal the damaged chromosome ends; or an anti-apoptotic response may be triggered by the hypoxic induction of telomerase (56-58).

\section{Telomerase activity and stress exposure in intrauterine life}

A rapidly growing body of empirical evidence suggests that a major burden of disease can be traced back to the intrauterine period of life. Importantly the sensitive biological functions of fetal cell proliferation, differentiation and maturation respond to, or are affected by conditions in the internal or external environment. The result of these responses are structural and/or functional changes in cells, tissues and organ systems that have important long-term consequences for subsequent health and disease susceptibility (59). Exposure to psychosocial stress and/or biological stress mediators during gestation has been identified as a condition that may modulate the long-term programming effects of the intrauterine environment (60).

Indeed, exposure to psychosocial stress during gestation appears to be an important risk factor for the earlier onset of complex, common age-related diseases (60). 
Table I. Correlation of telomere length and telomerase activity with pregnancy complications.

Telomerase activity and telomere length

Decreased telomerase activity and telomere length is reduced

Higher telomerase activity in the larger twin than the smaller twin

Increased telomerase activity

Absence of telomerase results in aberrant fertilization

Decreased telomerase activity could be expected

Low protein diet during gestation leads to fewer large

telomeres and more short telomeres

Increased telomerase activity and no differences in fetal telomere length

between normal pregnancy and gestational hypertension

Increased telomerase activity but fetal telomere length is shorter

in gestational diabetes than that of normal pregnancy
Pregnancy complications

Intrauterine growth restriction (IUGR)

Growth discordant twins

Hypoxia

In vivo and in vitro fertilization treatment

Stress exposure in intrauterine life

Maternal nutrition

Hypertensive disorders

Gestational diabetes or diabetes
Studies on humans have demonstrated links between chronic or excessive psychosocial stress exposure and telomere biology $(5,61,62)$. These data suggest that stress-related changes in telomere integrity may be a possible mechanism linking psychosocial stress and age-related disease (63). Indeed, accelerated telomere shortening reflects stress-related oxidative damage to cells and increased aging (64). Substantial evidence supports the hypothesis that depression creates abnormalities in stress-related biological outcomes. Thus, individuals with mood disorders have a significantly shorter TL compared with stable individuals, representing as much as 10 years of accelerated aging (64). Furthermore, it has been demonstrated that exposure to a major stress hormone, such as cortisol, is associated with the downregulation of TA in activated human T lymphocytes (65). This is highly relevant, as leukocyte TL is a predictor of age-related disease onset and mortality (66). There is also the question of whether cellular aging is related to patterns of allostasis (66). Telomeric DNA quantity, DNA damage and heat shock protein gene expression have been used as physiological stress markers in chickens (67). Exposure to maternal psychological stress during intrauterine life appears to induce not only adverse birth and neonatal outcomes, but also subsequent health and disease risk-related outcomes over the lifespan of an individual. The relevant outcomes include metabolic, endocrine, immune and cognitive processes (5). One important question that has yet to be addressed is whether exposure to stress during intrauterine development can produce variations in TL, thereby potentially setting up a long-term trajectory at birth that defines or contributes to individual susceptibility for complex and common age-related diseases. Entringer et al (59) examined the TL in leukocytes of individuals whose mothers had experienced a high level of psychological stress during pregnancy. These authors demonstrated that exposure to maternal psychosocial stress during intrauterine life was associated with a significantly shorter TL in young adulthood (59). Additionally, it has been suggested that maternal psychological stress during pregnancy may exert a 'programming' effect on the developing telomere biology system that is already apparent at birth, as reflected by the setting of newborn TL (5). The association between TA and maternal stress exposure during pregnancy, has not yet been investigated and may shed further light on telomere biology. Indeed, it was postulated by Shalev et al (5) that a 'better understanding of the mechanisms that govern and regulate telomere biology throughout the lifespan may inform our understanding of etiology and the long-term consequences of stress and mental illnesses on aging processes in diverse populations and settings'.

\section{Telomerase activity and maternal nutrition}

A close correlation between general nutrition and longevity has been well-established. Importantly, nutrition is a key factor supporting normal pregnancy and refers to the consumption of nutrients and the diet of the mother before, during and after pregnancy. The nutrition of the fetus begins as early as conception. Thus, the nutritional status of the pregnant women is important as early as conception, and continues to be important throughout gestation and after birth during breastfeeding. It has been demonstrated that the nutrition of the mother is crucial as it may have an effect on the future health of the child; poor nutririon during pregrancy may lead to health complications in the later life of the child, and may lead to the development of cancer, cardiovascular disease, hypertension and diabetes (68). An inadequate or excessive amount of certain nutrients may lead to malformations or medical problems in the fetus and in the life of the developint child. Indeed, neurological disorders and handicaps of the fetus are more common in pregnant women who are malnourished (69). As $23.8 \%$ of babies worldwide are estimated to be born with lower than optimal weights at birth due to the lack of proper and sufficient nutrition, malnutrition poses a major risk to the health of the fetus (70). In particular, personal habits, such as smoking, excessive alcohol and caffeine consumption, the use of certain medications and illegal drugs can negatively and irreversibly affect the development of the fetus, and these negative effects can take place during the early stages of pregnancy. Moreover, maternal malnutrition generates offspring with a low birth weight (71). Specifically, a diet low in protein during gestation has no effect on placental weight, but results in a decreased weight of the offspring (72). Importantly, malnutrition in female rats has been shown to increase the production of the superoxide free radical (O2-) (73). It is well established that oxidative damage is a major feature of the aging process and can lead to telomere shortening (74), which is 
associated with cellular senescence in vitro and in vivo $(75,76)$. These data lead to the conclusion that increased cell apoptosis in the offspring can be caused by maternal protein restriction (75).

Importantly, maternal diet was found to influence TL in the rat offspring $(77,78)$. Thus, the offspring of mothers who consumed a diet low in protein during gestation had significantly shorter telomeres compared to the controls. In addition, maternal protein restriction during lactation increased longevity and reduced renal telomere shortening compared with offspring that were maternally protein-restricted in utero and then suckled by normally fed dams (79). The nutritional programming of coenzyme $\mathrm{Q}$ was found to be relevant to aortic TL in rats with different gestational regimes of this coenzyme (80). The correlation between telomerase biology and various pregnancy complications is summarized in Table I.

\section{Conclusions}

The functions of telomerase and telomeres have been examinedin many aspects of reproduction biology, such as fertilization, placental development, stress and hypoxia conditions during pregnancy, as well as premature aging following IUGR. Importantly, varying TA activity has been shown during the progression of normal pregnancies; TA activity being significantly higher in the early as compared to the late gestation period. It is noteworthy that under pregnancy-related pathological conditions, TA is decreased or absent, which results in significantly shorter telomeres. In depth studies on telomere biology during reproduction can improve our understanding of the significance of telomerase in fetal development and lifelong consequences on illnesses and aging processes in different populations. This understanding may lead to better prevention policies and may perhaps reveal novel therapeutic strategies.

\section{References}

1. Hewitt G, Jurk D, Marques FD, Correia-Melo C, Hardy T, Gackowska A, Anderson R, Taschuk M, Mann J and Passos JF: Telomeres are favoured targets of a president DNA damage in ageing and stress-induced senescence. Nat Commun 3: 708, 2012.

2. Shay JW and Wright WE: Senescence and immortalization: Role of telomeres and telomerase. Carcinogenesis 26: 867-874, 2005.

3. Collins K: The biogenesis and regulation of telomerase holoenzymes. Nat Rev Mol Cell Biol 7: 484-494, 2006.

4. Harley CB, Futcher AB and Greider CW: Telomeres shorten during ageing of human fibroblasts. Nature 345: 458-460, 1990.

5. Shalev I, Entringer S, Wadhwa PD, Wolkowitz OM, Puterman E, Lin J and Epel ES: Stress and telomere biology: A lifespan perspective. Psychoneuroendocrinology 38: 1835-1842, 2013.

6. Armanios M and Blackburn EH: The telomere syndromes. Nat Rev Genet 13: 693-704, 2012.

7. Takai H, Smogorzewska A and de Lange T: DNA damage foci at dysfunctional telomeres. Curr Biol 13: 1549-1556, 2003.

8. d'Adda di Fagagna F, Reaper PM, Clay-Farrace L, Fiegler H, Carr P, Von Zglinicki T, Saretzki G, Carter NP and Jackson SP: A DNA damage checkpoint response in telomere-initiated senescence. Nature 426: 194-198, 2003.

9. Abdalla HI, Burton G, Kirkland A, Johnson MR, Leonard T, Brooks AA and Studd JW: Age, pregnancy and miscarriage: Uterine versus ovarian factors. Hum Reprod 8: 1512-1517, 1993.

10. Janny L and Menezo YJ: Maternal age effect on early human embryonic development and blastocyst formation. Mol Reprod Dev 45: 31-37, 1996.

11. Wright WE, Piatyszek MA, Rainey WE, Byrd W and Shay JW: Telomerase activity in human germline and embryonic tissues and cells. Dev Genet 18: 173-179, 1996.

12. Allsopp R, Shimoda J, Easa D and Ward K: Long telomeres in the mature human placenta. Placenta 28: 324-327, 2007.
13. Liu L, Blasco M, Trimarchi J and Keefe D: An essential role for functional telomeres in mouse germ cells during fertilization and early development. Dev Biol 249: 74-84, 2002.

14. Orly J: Molecular events defining follicular developments and steroidogenesis in the ovary. In: Gene engineering in endocrinology. Shupnik MA (ed). Humana Press Inc., Totowa, NJ, pp239-276, 2001.

15. Klinger FG and De Felici M: In vitro development of growing oocytes from fetal mouse oocytes: Stage-specific regulation by stem cell factor and granulosa cells. Dev Biol 244: 85-95, 2002.

16. Russo V, Berardinelli P, Capacchietti G and Scapolo PA: Localization of the telomerase catalytic subunit (TERT) in pig ovarian follicles. Vet Res Commun 27 (Suppl 1): 623-626, 2003.

17. Liu W and Zhu GJ: Expression of telomerase in human ovarian luteinized granulosa cells and its relationship to ovarian function. Zhonghua Fu Chan Ke Za Zhi 38: 402-404, 2003 (In Chinese).

18. Kinugawa C, Murakami T, Okamura K and Yajima A: Telomerase activity in normal ovaries and premature ovarian failure. Tohoku J Exp Med 190: 231-238, 2000.

19. Johnson JE, Higdon HL III and Boone WR: Effect of human granulosa cell co-culture using standard culture media on the maturation and fertilization potential of immature human oocytes. Fertil Steril 90: 1674-1679, 2008.

20. Heng BC, Tong GQ and Ng SC: Effects of granulosa coculture on in-vitro oocyte meiotic maturation within a putatively less competent murine model. Theriogenology 62: 1066-1092, 2004.

21. Biron-Shental T, Kidron D, Sukenik-Halevy R, GoldbergBittman L, Sharony R, Fejgin MD and Amiel A: TERC telomerase subunit gene copy number in placentas from pregnancies complicated with intrauterine growth restriction. Early Hum Dev 87: 73-75, 2011

22. Lavranos TC, Mathis JM, Latham SE, Kalionis B, Shay JW and Rodgers RJ: Evidence for ovarian granulosa stem cells: Telomerase activity and localization of the telomerase ribonucleic acid component in bovine ovarian follicles. Biol Reprod 61: 358-366, 1999.

23. Cheng EH, Chen SU, Lee TH, Pai YP, Huang LS, Huang CC and Lee MS: Evaluation of telomere length in cumulus cells as a potential biomarker of oocyte and embryo quality. Hum Reprod 28: 929-936, 2013.

24. Chen H, Wang W, Mo Y, Ma Y, Ouyang N, Li R, Mai M, He Y, Bodombossou-Djobo MM and Yang D: Women with high telomerase activity in luteinised granulosa cells have a higher pregnancy rate during in vitro fertilisation treatment. J Assist Reprod Genet 28: 797-807, 2011.

25. Butts S, Riethman H, Ratcliffe S, Shaunik A, Coutifaris C and Barnhart K: Correlation of telomere length and telomerase activity with occult ovarian insufficiency. J Clin Endocrinol Metab 94: 4835-4843, 2009.

26. Wang W, Chen H, Li R, Ouyang N, Chen J, Huang L, Mai M, Zhang N, Zhang Q and Yang D: Telomerase activity is more significant for predicting the outcome of IVF treatment than telomere length in granulosa cells. Reproduction 147: 649-657, 2014.

27. Keefe DL, Franco S, Liu L, Trimarchi J, Cao B, Weitzen S, Agarwal S and Blasco MA: Telomere length predicts embryo fragmentation after in vitro fertilization in women - toward a telomere theory of reproductive aging in women. Am J Obstet Gynecol 192: 1256-1260, discussion 1260-1261, 2005.

28. Chen RJ, Chu CT, Huang SC, Chow SN and Hsieh CY: Telomerase activity in gestational trophoblastic disease and placental tissue from early and late human pregnancies. Hum Reprod 17: 463-468, 2002.

29. Izutsu T, Kudo T, Sato T, Nishiya I, Ohyashiki K and Nakagawara K: Telomerase and proliferative activity in placenta from women with and without fetal growth restriction. Obstet Gynecol 93: 124-129, 1999.

30. Nishi H, Yahata N, Ohyashiki K, Isaka K, Shiraishi K, Ohyashiki JH, Toyama K and Takayama M: Comparison of telomerase activity in normal chorionic villi to trophoblastic diseases. Int J Oncol 12: 81-85, 1998.

31. Kyo S, Takakura M, Tanaka M, Kanaya T, Sagawa T, Kohama T, Ishikawa $\mathrm{H}$, Nakano T, Shimoya $\mathrm{K}$ and Inoue M: Expression of telomerase activity in human chorion. Biochem Biophys Res Commun 241: 498-503, 1997.

32. Biron-Shental T, Sukenik Halevy R, Goldberg-Bittman L, Kidron D, Fejgin MD and Amiel A: Telomeres are shorter in placental trophoblasts of pregnancies complicated with intrauterine growth restriction (IUGR). Early Hum Dev 86: 451-456, 2010.

33. Cosmi E, Fanelli T, Visentin S, Daniele T and Zanardo V: Consequences in infants the were intrauterine growth restricted. J Pregnancy 2011: 364381, 2011. 
34. Kudo T, Izutsu T and Sato T: Telomerase activity and apoptosis as indicators of ageing in placenta with and without intrauterine growth retardation. Placenta 21: 493-500, 2000.

35. Izutsu T, Kudo T, Sato T, Nishiya I, Ohyashiki K, Mori M and Nakagawara K: Telomerase activity in human chorionic villi and placenta determined by TRAP and in situ TRAP assay. Placenta 19: 613-618, 1998.

36. Izutsu T, Izutsu N, Iwane A, Takada A, Nagasawa T, Kanasugi T and Sugiyama T: Expression of human telomerase reverse transcriptase and correlation with telomerase activity in placentas with and without intrauterine growth retardation. Acta Obstet Gynecol Scand 85: 3-11, 2006.

37. Davy P, Nagata M, Bullard P, Fogelson NS and Allsopp R: Fetal growth restriction is associated with accelerated telomere shortening and increased expression of cell senescence markers in the placenta. Placenta 30: 539-542, 2009.

38. Breathnach FM and Malone FD: Fetal growth disorders in twin gestations. Semin Perinatol 36: 175-181, 2012.

39. Banks CL, Nelson SM and Owen P: First and third trimester ultrasound in the prediction of birthweight discordance in dichorionic twins. Eur J Obstet Gynecol Reprod Biol 138: 34-38, 2008.

40. Kim SY, Lee SP, Lee JS, Yoon SJ, Jun G and Hwang YJ: Telomerase and apoptosis in the placental trophoblasts of growth discordant twins. Yonsei Med J 47: 698-705, 2006.

41. Jauniaux E, Gulbis B and Burton GJ: The human first trimester gestational sac limits rather than facilitates oxygen transfer to the foetus - a review. Placenta 24 (Suppl A): S86-S93, 2003.

42. Giaccia AJ, Simon MC and Johnson R: The biology of hypoxia: The role of oxygen sensing in development, normal function, and disease. Genes Dev 18: 2183-2194, 2004.

43. Ream M, Ray AM, Chandra R and Chikaraishi DM: Early fetal hypoxia leads to growth restriction and myocardial thinning. Am J Physiol Regul Integr Comp Physiol 295: R583-R595, 2008.

44. Carter AM: Placental oxygen consumption. Part I: In vivo studies - a review. Placenta 21 (Suppl A): S31-S37, 2000.

45. Anderson RN: Deaths: Leading causes for 2000. Natl Vital Stat Rep 50: 1-85, 2002.

46. Hutter D, Kingdom J and Jalggi E: Causes and mechanisms of intrauterine hypoxia and its impact on the fetal cardiovascular system: a review. Int J Pediatr 2010: 401323, 2010.

47. Miller SL, Huppi PS and Mallard C: The consequences of fetal growth restriction on brain structure and neurodevelopmental outcome. J Physiol 594: 807-823, 2016.

48. Faa G, Marcialis MA, Ravarino A, Piras M, Pintus MC and Fanos V: Fetal programming of the human brain: Is there a link with insurgence of neurodegenerative disorders in adulthood? Curr Med Chem 21: 3854-3876, 2014

49. Sutter CH, Laughner E and Semenza GL: Hypoxia-inducible factor $1 \alpha$ protein expression is controlled by oxygen-regulated ubiquitination that is disrupted by deletions and missense mutations. Proc Natl Acad Sci USA 97: 4748-4753, 2000.

50. Wang GL, Jiang BH, Rue EA and Semenza GL: Hypoxia-inducible factor 1 is a basic-helix-loop-helix-PAS heterodimer regulated by cellular O2 tension. Proc Natl Acad Sci USA 92: 5510-5514, 1995

51. Yatabe N, Kyo S, Maida Y, Nishi H, Nakamura M, Kanaya T, Tanaka M, Isaka K, Ogawa S and Inoue M: HIF-1-mediated activation of telomerase in cervical cancer cells. Oncogene 23 : 3708-3715, 2004.

52. Iyer NV, Kotch LE, Agani F, Leung SW, Laughner E, Wenger RH, Gassmann M, Gearhart JD, Lawler AM, Yu AY, et al: Cellular and developmental control of $\mathrm{O} 2$ homeostasis by hypoxia-inducible factor $1 \alpha$. Genes Dev 12: 149-162, 1998.

53. Sukenik-Halevy R, Fejgin M, Kidron D, Goldberg-Bittman L, Sharony R, Biron-Shental T, Kitay-Cohen Y and Amiel A: Telomere aggregate formation in placenta specimens of pregnancies complicated with pre-eclampsia. Cancer Genet Cytogenet 195: 27-30, 2009.

54. Nishi H, Nakada T, Kyo S, Inoue M, Shay JW and Isaka K: Hypoxia-inducible factor 1 mediates upregulation of telomerase (hTERT). Mol Cell Biol 24: 6076-6083, 2004.

55. Guan JZ, Guan WP, Maeda T and Makino N: Different levels of hypoxia regulate telomere length and telomerase activity. Aging Clin Exp Res 24: 213-217, 2012.

56. Coussens M, Davy P, Brown L, Foster C, Andrews WH, Nagata M and Allsopp R: RNAi screen for telomerase reverse transcriptase transcriptional regulators identifies HIF1alpha as critical for telomerase function in murine embryonic stem cells. Proc Natl Acad Sci USA 107: 13842-13847, 2010.

57. Stewart SA and Weinberg RA: Telomerase and human tumorigenesis. Semin Cancer Biol 10: 399-406, 2000.
58. Zhang P, Chan SL, Fu W, Mendoza M and Mattson MP: TERT suppresses apoptotis at a premitochondrial step by a mechanism requiring reverse transcriptase activity and 14-3-3 protein-binding ability. FASEB J 17: 767-769, 2003.

59. Entringer S, Epel ES, Kumsta R, Lin J, Hellhammer DH, Blackburn EH, Wüst S and Wadhwa PD: Stress exposure in intrauterine life is associated with shorter telomere length in young adulthood. Proc Natl Acad Sci USA 108: E513-E518, 2011.

60. Cohen S, Janicki-Deverts D and Miller GE: Psychological stress and disease. JAMA 298: 1685-1687, 2007.

61. Epel ES, Blackburn EH, Lin J, Dhabhar FS, Adler NE, Morrow JD and Cawthon RM: Accelerated telomere shortening in response to life stress. Proc Natl Acad Sci USA 101: 17312-17315, 2004.

62. Monaghan P: Organismal stress, telomeres and life histories. J Exp Biol 217: 57-66, 2014.

63. Kiecolt-Glaser JK and Glaser R: Psychological stress, telomeres, and telomerase. Brain Behav Immun 24: 529-530, 2010.

64. Simon NM, Smoller JW, McNamara KL, Maser RS, Zalta AK, Pollack MH, Nierenberg AA, Fava M and Wong KK: Telomere shortening and mood disorders: Preliminary support for a chronic stress model of accelerated aging. Biol Psychiatry 60: 432-435, 2006.

65. Choi J, Fauce SR and Effros RB: Reduced telomerase activity in human T lymphocytes exposed to cortisol. Brain Behav Immun 22: 600-605, 2008.

66. Tomiyama AJ, O'Donovan A, Lin J, Puterman E, Lazaro A, Chan J, Dhabhar FS, Wolkowitz O, Kirschbaum C, Blackburn E, et al: Does cellular aging relate to patterns of allostasis? An examination of basal and stress reactive HPA axis activity and telomere length. Physiol Behav 106: 40-45, 2012.

67. Sohn SH, Subramani VK, Moon YS and Jang ISL: Telomeric DNA quantity, DNA damage, and heat shock protein gene expression as physiological stress markers in chickens. Poult Sci 91: 829-836, 2012

68. Wood-Bradley RJ, Barrand S, Giot A and Armitage JA: Understanding the role of maternal diet on kidney development; an opportunity to improve cardiovascular and renal health for future generations Nutrients 7: 1881-1905, 2015

69. Kerac M, Postels DG, Mallewa M, Alusine Jalloh A, Voskuijl WP, Groce N, Gladstone M and Molyneux E: The interaction of malnutrition and neurologic disability in Africa Semin Pediatr Neurol 21: 42-49, 2014

70. Nnam NM: Improving maternal nutrition for better pregnancy outcomes. Proc Nutr Soc 74: 454-459, 2015

71. Petry CJ, Dorling MW, Pawlak DB, Ozanne SE and Hales CN: Diabetes in old male offspring of rat dams fed a reduced protein diet. Int J Exp Diabetes Res 2: 139-143, 2001.

72. Snoeck A, Remacle C, Reusens B and Hoet JJ: Effect of a low protein diet during pregnancy on the fetal rat endocrine pancreas. Biol Neonate 57: 107-118, 1990.

73. Franco MC, Akamine EH, Di Marco GS, Casarini DE, Fortes ZB, Tostes RC, Carvalho MH and Nigro D: NADPH oxidase and enhanced superoxide generation in intrauterine undernourished rats: Involvement of the renin-angiotensin system. Cardiovasc Res 59: 767-775, 2003

74. Richter T and von Zglinicki T: A continuous correlation between oxidative stress and telomere shortening in fibroblasts. Exp Gerontol 42: 1039-1042, 2007.

75. Sekoguchi S, Nakajima T, Moriguchi M, Jo M, Nishikawa T, Katagishi T, Kimura H, Minami M, Itoh Y, Kagawa K, et al: Role of cell-cycle turnover and oxidative stress in telomere shortening and cellular senescence in patients with chronic hepatitis C. J Gastroenterol Hepatol 22: 182-190, 2007.

76. Petrik J, Reusens B, Arany E, Remacle C, Coelho C, Hoet JJ and Hill DJ: A low protein diet alters the balance of islet cell replication and apoptosis in the fetal and neonatal rat and is associated with a reduced pancreatic expression of insulin-like growth factor-II. Endocrinology 140: 4861-4873, 1999.

77. Tarry-Adkins JL, Chen JH, Smith NS, Jones RH, Cherif H and Ozanne SE: Poor maternal nutrition followed by accelerated postnatal growth leads to telomere shortening and increased markers of cell senescence in rat islets. FASEB J 23: 1521-1528, 2009.

78. Tarry-Adkins JL, Martin-Gronert MS, Chen JH, Cripps RL and Ozanne SE: Maternal diet influences DNA damage, aortic telomere length, oxidative stress, and antioxidant defense capacity in rats. FASEB J 22: 2037-2044, 2008.

79. Jennings BJ, Ozanne SE, Dorling MW and Hales CN: Early growth determines longevity in male rats and may be related to telomere shortening in the kidney. FEBS Lett 448: 4-8, 1999.

80. Tarry-Adkins JL, Fernandez-Twinn DS, Chen JH, Hargreaves IP, Martin-Gronert MS, McConnell JM and Ozanne SE: Nutritional programming of coenzyme Q: Potential for prevention and intervention? FASEB J 28: 5398-5405, 2014. 